\title{
Clinical Decision Support in the Pediatric Hospital Setting
}

\author{
Levon Utidjian, M.D. ${ }^{1, *}$ \\ Eric Kirkendall, M.D., M.B.I. ${ }^{2}$ \\ Eric Shelov, M.D. ${ }^{3}$
}

\author{
Address \\ ${ }^{*}, 1$ Division of General Pediatrics, Department of Biomedical and Health Informatics, \\ The Children's Hospital of Philadelphia, 3535 Market Street, Suite 1024, Philadelphia, \\ PA 19104, USA \\ Email: utidjianl@email.chop.edu \\ ${ }^{2}$ Division of Biomedical Informatics, Division of Hospital Medicine, Department of \\ Pediatrics, Cincinnati Children's Hospital Medical Center, 3333 Burnet Avenue, \\ ML-5035, Cincinnati, OH 45229, USA \\ ${ }^{3}$ Division of General Pediatrics, The Children's Hospital of Philadelphia, 3401 Civic \\ Center Boulevard, Room 12NW-70, Philadelphia, PA 19104, USA
}

Published online: 19 December 2014

(C) Springer International Publishing AG 2014

This article is part of the Topical Collection on Hospital Medicine

Keywords Electronic health record - Clinical decision support systems - Decision support systems - Electronic medical record · Computer-assisted decision-making

\section{Opinion statement}

The electronic health record (EHR) is a key component in the delivery of healthcare in most hospitals in the USA today. Current EHR systems have evolved from simple databases for basic administrative and patient information to complex systems that are also capable of storing clinical documentation, laboratory results, and radiologic images, as well as transmitting patient care orders throughout a hospital's various departments and systems. Within the EHR, clinical decision support (CDS) tools have the potential to help improve patient care by standardizing practice, reducing errors, and aiding diagnostic and therapeutic decision-making. In the pediatric hospital setting, CDS tools can deliver pediatricspecific information and guidance on disease management through alerts, computerized provider order entry and order sets, and clinical practice guidelines. These various CDS functions are of great importance to the practice of safe, high-quality patient care and learning to maximize their potential is of great benefit to clinicians. At the same time, these tools must be implemented in a manner consistent with established CDS best practices to prevent potential unintended consequences that introduce new sources of error and potential harm. 


\section{Introduction}

The US healthcare system is in an era of increased focus on the quality and value of the care delivered to patients. The electronic health record (EHR) has long been viewed as a means of transforming healthcare by improving care quality and patient safety [1]. The federal government's passage of the American Recovery and Reinvestment Act in 2009 included specific funding through the Health Information Technology for Economic and Clinical Health (HITECH) Act to help spur the adoption of health information technology $[2,3]$. Over the last 5 years, the percentage of hospitals with basic EHRs has steadily increased from $9.4 \%$ in 2008 to $59.4 \%$ in 2013 [4]. However, the goal of the HITECH Act is not to simply install an EHR system in every clinic and hospital but to do so in a way that positively impacts the quality of care patients receive. As such, a portion of the HITECH Act's funding was designated for the Meaningful Use program, which offers financial incentives not only for installing EHR systems but also for utilizing them in a way that leads to improved patient outcomes [5]. To realize the goal of the Meaningful Use program, the EHR must be more than just a database that stores basic administrative and clinical data but also a system capable of assisting clinicians in the delivery of better, safer care.

An important means by which EHR systems can achieve this goal of higher quality care is through the use of clinical decision support (CDS) tools. CDS in the EHR presents clinicians with "knowledge and personspecific information, intelligently filtered or presented at appropriate times, to enhance health and health care [6]."
These tools can combine biomedical knowledge with patient data in the EHR, present the clinician with patient and disease-specific information, and potentially provide recommendations for diagnostic or therapeutic decision-making. CDS ideally follows the "five rights," presenting the right information, to the right person, in the right format, via the right channel, at the right time in the care process [7].

CDS tools are not new to medicine and have existed in many different forms, such as disease-specific documentation and paper-based order templates, published clinical treatment guidelines, and drug reference guides. CDS tools integrated within the EHR can take this further, presenting such information to clinicians in a context-specific manner so that they do not need to actively seek or recall the information. This can, in turn, save time, reduce errors, and reduce the cognitive burden on providers $[8 \bullet \bullet$, Class IV, 9].

As most commercial EHR systems are designed for the care of adults, special attention must be given to configuring these systems for use in pediatric settings. This is especially important in hospitals that care for both adult and pediatric patients where the same EHR must address the needs of both patient populations. This article will review some of the most commonly encountered CDS tools in pediatric hospitals, highlighting the known benefits and best practices to help avoid potential unintended consequences of their use, and conclude with an integrated real-life example of CDS in action.

\section{Clinical decision support tools}

\section{Addressing pediatric-specific needs}

In order to deliver effective CDS in pediatric care settings, an EHR must be configured to capture pediatric-specific data elements and be able to factor in a patient's age, growth dimensions, and history into decision support recommendations. Some patient data elements unique to the pediatric population include birth history information, gestational age, developmental milestones, and a more complex immunization schedule than seen with adult patients. The determination of normal versus abnormal values for reference ranges can be particularly challenging as they change much more quickly than those in adults. Reference ranges for laboratory results and vital sign data typically vary with age, while normal ranges for blood pressure interpretation requires a combination 
of gender, age, and height information. Such pediatric-specific considerations are not standard features in all commercial EHRs and can require careful customization with stakeholders from various hospital departments. This lack of standard pediatric-specific features is a commonly noted barrier to pediatric EHR adoption [10, 11].

An American Academy of Pediatrics (AAP) policy statement outlined several requirements for a pediatric EHR in ambulatory and hospital settings [12]. While certain functions like immunization management and growth tracking are more commonly used in ambulatory settings, some examples more relevant to hospital settings include the following:

- Medication dosing: dosing by weight, dose-range checking, rounding to safe and convenient doses, age-based decision support

- Patient identification: newborn and prenatal identifiers, name changes, ambiguous sex

- Norms for pediatric data: numeric values, non-numeric, complex normative data like blood pressure, and gestational age

- Privacy: children in foster or custodial care, consent, adoption, guardianship

The risks of adult-oriented EHR systems lacking such pediatric-specific data and functions earned this issue a spot on the ECRI Institute's 2014 Top 10 Health Technology Hazards list [13]. In a recent effort to address this issue, the Agency for Healthcare Research and Quality (AHRQ) released the children's EHR format, which provides a set of child-specific requirements that an EHR should meet in order to optimally meet the healthcare needs of children [14•, class IV]. The children's EHR format assists EHR vendors in their efforts to develop systems that meet the needs of children and helps guide potential customers in their selection of an EHR by ensuring it meets these minimum requirements.

Alerts are not only one the most frequently encountered CDS tools but also one of the most challenging to implement successfully and without unintended consequences. The goal of any alert is to offer clinicians information and guidance that could be useful in decision-making during patient care. Such alerts might prompt clinicians about routine health maintenance needs such as recommended screening tests or vaccinations or medication-related warnings $[15,16]$. Examples of common type of alerts are shown in Table 1.

Such alerts can help overcome clinician gaps in knowledge, which is a challenge with the rapid growth of the medical literature, changing screening recommendations, and increasing numbers of possible medications. They can help avoid errors of commission by warning the clinician of the potential harm of an action and omission by reminding the clinician of a needed test or treatment $[8 \bullet \bullet$.

In designing alerts, special attention must be paid to ensure the content is relevant for pediatrics. Some alerts more likely to be encountered in pediatric settings include special diet concerns (e.g., ketogenic diet as part of seizure management) and behavioral concerns (e.g., developmental delays and 


\section{Table 1. Examples of common CDS alerts}

\begin{tabular}{|c|c|}
\hline Alert type & Example \\
\hline Health maintenance reminder & Clinician receives a reminder that a patient is overdue for an annual influenza vaccination \\
\hline Drug-drug interaction alert & $\begin{array}{l}\text { As a clinician is ordering digoxin, they receive a warning that the patient is on furosemide } \\
\text { and there is a potential toxicity risk through this drug combination }\end{array}$ \\
\hline Drug-allergy alert & $\begin{array}{l}\text { As a clinician is ordering amoxicillin, they receive a warning that the patient has a penicillin } \\
\text { allergy }\end{array}$ \\
\hline Event-driven alert & A patient's lab result is a critical value and the EHR alerts the physician \\
\hline Cost-effectiveness alert & $\begin{array}{l}\text { Clinician receives an alert that an order for a blood test they are trying to place is a duplicate } \\
\text { test }\end{array}$ \\
\hline
\end{tabular}

impaired communication requiring specialized care). Some medication-related alerts may need greater granularity than those in adults, with consideration of a patient's age regarding the potential toxicity of medications due to differences in metabolism. Careful consideration of the clinical workflow is also vital to minimize interruption, and that guiding the clinician to the right decision is always better than stopping them after the wrong one. The overall goal of an alert is to provide minimally intrusive, contextually aware information that contains a recommendation for action.

Although alerts have the potential to assist clinicians throughout a patient's course of treatment, their indiscriminate provision can carry the unintended consequence of creating new kinds of errors [17]. An ideal CDS alerting system would only display interruptive alerts for actions that pose a serious risk of harm to the patient and would appear only when absolutely necessary. If the alerting system provides an excessive amount of alerts of low risk that are frequently overridden, clinicians may become conditioned to habitually ignoring any alert they see. Such "alert fatigue" can then lead a clinician to unintentionally override a potentially serious alert that was lost in the noise of too many nuisance alerts [18-21]. This issue of alert fatigue in the EHR, as well as excessive alarming of medical devices and monitors throughout the hospital, has held the top spot of the ECRI Institute's Top 10 Health Technology Hazards for the last 3 years [13]. Thus, before creating any new alert, one should carefully examine the existing alerts provided in the EHR system, particularly those overridden most frequently. After implementation, an evaluation plan should be enacted to ensure the alert is effective and not burdensome to care providers.

\section{Computerized provider order entry}

Computerized provider order entry (CPOE) is defined by the AHRQ as "an application that enables providers to enter medical orders into a computer system that is located within an inpatient or ambulatory setting [22]." The " $\mathrm{P}^{\prime \prime}$ in CPOE has transitioned from "physician" to "provider" over the years, in recognition of the increasing importance of the functionality to all care providers that can place orders, not just physicians. E-prescribing is oftentimes described as CPOE limited to prescribing only. CPOE takes on many forms in many systems, from a stand-alone application to the core integrating functionality among a suite of software modules. In the Health Information Management Systems Society (HIMSS) Electronic Medical Record Adoption Model, 
healthcare providing organizations must adopt CPOE to achieve stage 4-7 status (the highest levels in the model). In addition, CPOE must be implemented for eligible providers and hospitals to claim Meaningful Use incentive payments [23].

CPOE can be viewed as both a platform and data source for CDS. Data entered into the CPOE interface can serve as input for software rules engines. A rules engine can use the data to provide the clinical context of the order, generate CDS by processing the input in conjunction with preset knowledgebased rules, and then output the CDS through the CPOE interface screen or other external viewing system. A common example of this of particular importance in pediatrics is drug dosing decision support. When providers enter a medication order in CPOE, most systems will reference a set of drug dosing rules to validate or refute the prescribed dose based on the context, displaying an alert to the clinician if the dose is out of an acceptable predetermined range. Implementation of pediatric-specific rules can be difficult in settings where the same CPOE system is used for adult care [24,25]. Other common forms of CDS related to $\mathrm{CPOE}$ include drug-drug interaction, drug-allergy checking, and immunization ordering support.

Many benefits of using CPOE with CDS tools have been demonstrated in the informatics literature. Given the predominance of dosing errors in pediatrics, it is no surprise that a significant portion of the evidence has demonstrated the reduction of these types of errors, although it should be noted that not all studies have been positive or shown a significant reduction in adverse drug events [26-31]. Other medication-related benefits include prescribing cheaper, but equally effective drugs [32]. CPOE has been shown to have widespread benefits beyond medication ordering and safety. These benefits include shorter times to dispense ordered medication, shorter lengths of stay for patients, reduction of redundant labs ordered, and increases in pharmacist productivity [33-35]. However, just as the benefits of CPOE use have varied, unintended consequences of CPOE have been well documented [36]. Information technology and clinical informatics experts should be involved in the design and implementation of CPOE systems to avoid the well-characterized mistakes [17, $37-40]$.

Order sets are curated collections of orders presented within a CPOE system, usually organized together with the goal of helping a provider efficiently accomplish specific clinical tasks (such as admit a patient with communityacquired pneumonia). Order sets may be comprised of many types of orders, but generally include medication orders, lab and radiology orders, nursing care orders, or orders for ancillary care. They are intended to reduce the cognitive workload of prescribers [9]. Many organizations with established CPOE systems (such as those of the authors) have hundreds of order sets available for clinical use. Despite the ubiquity of order sets and their perceived convenience, some researchers have found them costly to implement and use in some instances. However, this cost can be mitigated by data-driven design [41]. Order set content can be built de novo, acquired from the EHR vendor or community libraries, or can be purchased from a third party vendor. Regardless of the source, standardization of the order set build is imperative [42]. Order set 
builds can also have a positive impact on implementation through multidisciplinary involvement by engaging many different care providers, including physicians, nurses, respiratory therapists, and other hospital staff. The strong presence of organizational "special people" (supportive administrative leadership, clinical leadership, and other staff) will also have a positive impact on the success of CPOE implementation [43].

Order sets are constructed to minimize the time required for clinicians to order routine and guideline-driven tests and medications (e.g., setting default values for doses, duration, and testing intervals). They can also drive the adoption of evidence-based medicine and guideline use, can drive diagnosis recognition, and can create a perceived improvement in quality of care [44-47]. As with CPOE, order sets may also have unintended consequences (such as defaulting absolute medication dosing for patients that require weight-based dosing) that should be monitored [48].

The translation of clinical practice guidelines into electronic form can make use of several of the CDS tools already reviewed. Clinical practice guidelines are systematically developed statements to assist clinicians in their decision-making about the most appropriate care in specific clinical conditions [49]. They are based on the best available evidence in the medical literature and the consensus recommendations of clinical experts. Although following clinical practice guidelines helps ensure patients receive the appropriate tests and treatments, clinicians sometimes lack awareness and familiarity with guidelines, as well as the time to find them [50]. Clinical practice guideline-based CDS can help overcome these challenges, improving both guideline adherence and processes of care [51, 52].

Effective development of CDS to support clinical practice guidelines must begin with a clear understanding of the guidelines and what clinical data are needed to support them. The guideline's recommendations must be broken down into rules that a rules engine can then evaluate. The ability to leverage clinical data already entered into the EHR would help with the automatic provision of decision support and avoid the need for the provider to actively input data just to generate decision support recommendations. When the rules detect that a particular guideline is applicable to a patient, an alert can present the clinician with any recommended next steps [51]. The alert could even link directly to an order set

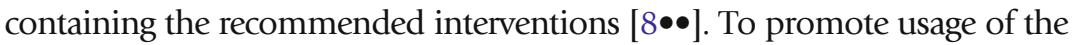
guideline, such alerts and opportunities to use the order sets should be available at the appropriate times in the clinician's workflow, which can vary by institution as well as by EHR system. Engaging those clinicians with the most knowledge about local workflow, such as residents and hospitalists, is important in identifying when and where such guideline-related CDS will be most effective.

Currently, there are more clinical practice guidelines for adult diseases and in some cases compliance is monitored by national organizations like The Joint Commission. The AAP and other pediatric subspecialty organizations have released guidelines for treatment of some pediatric diseases and the number continues to grow. Some such guidelines for the management of common pediatric diseases like asthma and acute otitis media have already been integrated into CDS within EHR systems and shown to improve clinician adherence to guidelines $[53,54]$. 
Example of multiple modes of CDS implemented to improve patient/family-centered patient care

Pediatric patients with acute viral gastroenteritis can have the duration of diarrhea shortened by the administration of probiotics [55]. However, the treatment effect is relatively short (about 1-day decrease in diarrhea) and usually comes at a modest out-of-pocket cost to patients, as probiotics are not covered by most forms of health insurance. This situation creates a tradeoff-a scenario where patient (and family) preference should play a large role in the medical decision-making process.

At one institution, CDS tools have been employed to increase appropriate provider prescription of probiotics [45]. The following is a list of the different modes of CDS used in that project, and Fig. 1 illustrates where they would fit into the course of the hospitalization:

1. Suggestions for the prescriber to use the acute gastroenteritis order set: within the CPOE interface, a non-interruptive prompt is visible if the patient has a chief complaint, diagnosis, or problem of diarrhea or gastroenteritis in the EHR.

2. Order sets were constructed with the following:

(a) Embedded evidence statements: succinct "one-liners" to inform the prescriber of applicable high-level evidence (e.g., the clinical effects of probiotics, proper fluid management, etc.)

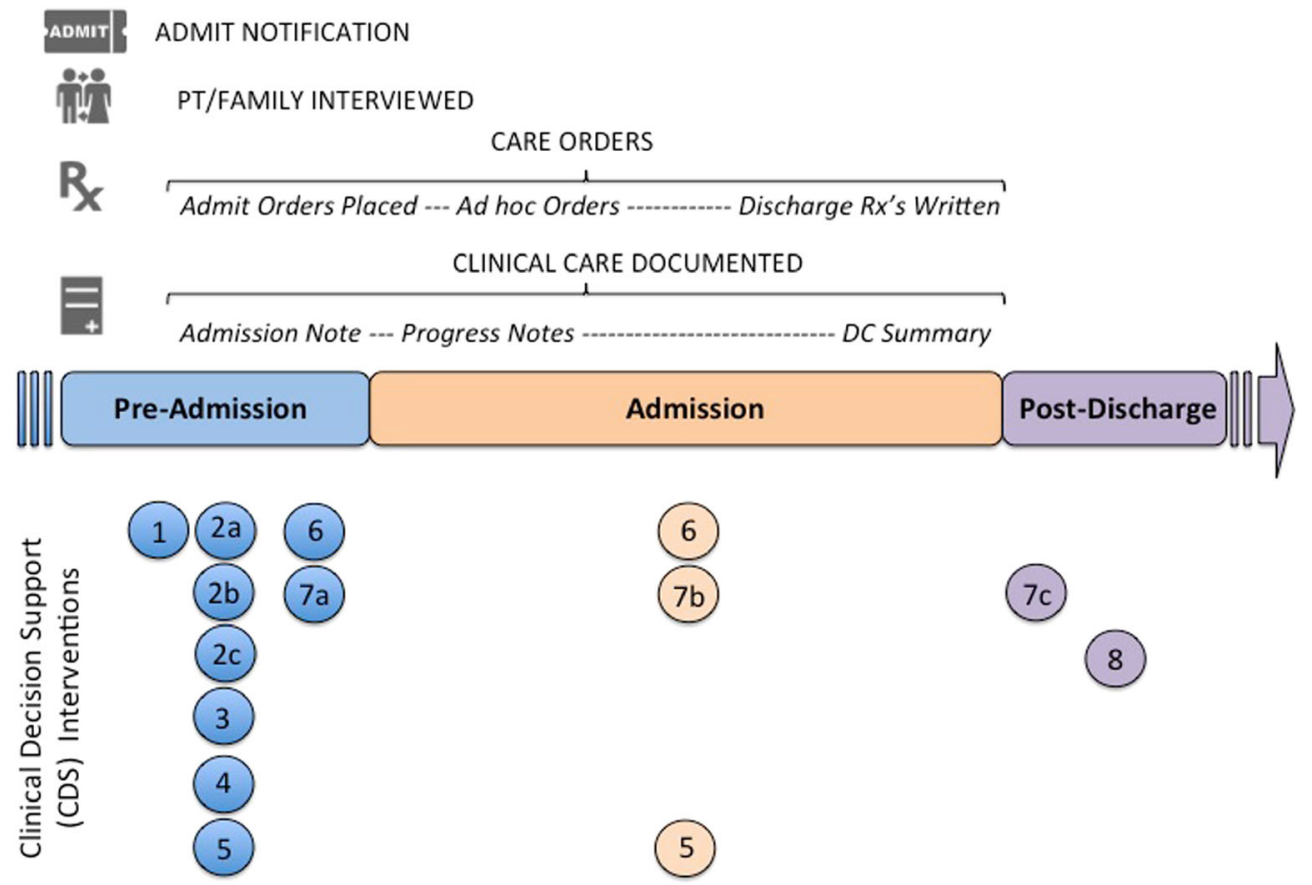

Figure 1. Diagram of CDS interventions along the phase of care in an inpatient pediatric patient. The numbers correspond to the CDS interventions listed in the example. 
(b) Directives to discuss the evidence and cost with families through a shared decision-making process

(c) Notifications of the availability of appropriate documentation templates

3. Orders for probiotics, with default dosing and other order parameters selected.

4. Corollary orders for isolation, with default-selection of orders to comply with organizational infection control measures.

5. Corollary orders for setting discharge goals and criteria: "physiologically ready" criteria are set at admission to encourage timely discharge of the patient.

6. Links to a shared decision-making aid: a website link to a shared decisionmaking tool designed for use at the bedside.

7. Documentation templates for the following:

(a) History and physical notes

(b) Progress notes

(c) Discharge summaries

8. Reporting elements: reporting elements were embedded into several of the documentation templates to aid in subsequent research data aggregation.

For this project, over a dozen different CDS tools were combined to improve the care of patients with acute gastroenteritis. These tools were an integral part of the project and helped increase the rate of proper prescription of probiotics to $100 \%$ by rapidly adopting evidence-based medicine and incorporating patient/family preference through shared decision-making. From the user perspective, the project was successful because it made the "right thing" to do, easy to do.

\section{Conclusion}

CDS tools provide a way to leverage the full potential of the EHR to deliver safe, high-quality patient care. These tools can enhance the abilities of clinicians to make better diagnostic and treatment decisions, as well as reduce many kinds of errors. However, to be as effective as possible, CDS tools should be implemented in a manner consistent with best known practices and with consideration of the potential unintended effects of even the most well-planned interventions.

\section{Compliance with Ethics Guidelines}

\section{Conflict of Interest}

Dr. Levon Utidjian declares that he has no conflict of interest. Dr. Eric Kirkendall declares that he has no conflict of interest. Dr. Eric Shelov declares that he has no potential conflicts of interest. 
Human and Animal Rights and Informed Consent

This article does not contain any studies with human or animal subjects performed by any of the authors.

\section{References and Recommended Reading}

References of particular interest, published recently, have been highlighted as:

- Of importance

$\bullet \quad$ Of major importance

1. Institute of Medicine (U.S.), Committee on Improving the Patient Record, Dick RS, Steen EB, Detmer DE. The computer-based patient record: an essential technology for health care. Washington, D.C.: National Academy Press; 1997.

2. Blumenthal D, Tavenner M. The "meaningful use" regulation for electronic health records. $\mathrm{N}$ Engl J Med. 2010;363(6):501-4.

3. Blumenthal D. Launching HITECH. N Engl J Med. 2010;362(5):382-5.

4. Charles D, Gabriel M, Furukawa MF. Adoption of electronic health record systems among U.S. nonfederal acute care hospitals: 2008-2013. Washington, DC: ONC Data Brief; 2014. p. 1-9.

5. Meaningful use [Internet]. HealthIT.gov. [cited 2013 Feb 20]. Available from: http://www.healthit.gov/ policy-researchers-implementers/meaningful-use.

6. Osheroff JA, Teich JM, Middleton B, Steen EB, Wright A, Detmer DE. A roadmap for national action on clinical decision support. J Am Med Inform Assoc. 2007;14(2):141-5.

7. Osheroff JA. Improving medication use and outcomes with clinical decision support: a step-by-step guide. Chicago: Healthcare Information and Management Systems Society Mission; 2009.

8.• Osheroff JA, Healthcare Information and Management Systems Society. Improving outcomes with clinical decision support: an implementer's guide. Chicago: HIMSS; 2012.

This authoritative guide on clinical decision support implementation is a valuable resource for understanding decision support best practices and applying them.

9. Avansino J, Leu MG. Effects of CPOE on provider cognitive workload: a randomized crossover trial. Pediatrics. 2012;130(3):e547-52.

10. Kim GR, Lehmann CU, Council on Clinical Information Technology. Pediatric aspects of inpatient health information technology systems. Pediatrics. 2008;122(6):e1287-96.

11. Nakamura MM, Ferris TG, DesRoches CM, Jha AK. Electronic health record adoption by children's hospitals in the United States. Arch Pediatr Adolesc Med Am Med Assoc. 2010;164(12):1145.

12. Spooner SA, Council on Clinical Information Technology, American Academy of Pediatrics. Special requirements of electronic health record systems in pediatrics. Pediatrics. 2007;119(3):631-7. 119.
13. ECRI Institute. Top 10 health technology hazards for 2014. 2013 Nov 1;1-16

14. Children's EHR Format - Documentation and User Guide. (Prepared by Westat under Contract No. HHSA 290-2009-00023I - Task Order 3, Domain 2.) AHRQ

Publication No. 13-0020-EF. Rockville, MD: Agency for Healthcare Research and Quality. November 2012.

This document serves as a useful reference guide for evaluating an EHR system by outlining minimum child-specific requirements to ensure the system will meet the healthcare needs of children.

15. Jha AK, DesRoches CM, Campbell EG, Donelan K, Rao SR, Ferris TG, et al. Use of electronic health records in U.S. hospitals. N Engl J Med. 2009;360(16):1628-38.

16. McCoy AB, Thomas EJ, Krousel-Wood M, Sittig DF. Clinical decision support alert appropriateness: a review and proposal for improvement. Ochsner J. 2014;14(2):195-202.

17. Campbell EM, Sittig DF, Ash JS, Guappone KP, Dykstra $\mathrm{RH}$. Types of unintended consequences related to computerized provider order entry. J Am Med Inform Assoc. 2006;13(5):547-56.

18. Koppel R, Metlay JP, Cohen A, Abaluck B, Localio AR, Kimmel SE, et al. Role of computerized physician order entry systems in facilitating medication errors. JAMA. 2005;293(10):1197-203.

19. van der Sijs H, Aarts J, Vulto A, Berg M. Overriding of drug safety alerts in computerized physician order entry. J Am Med Inform Assoc. 2006;13(2):138-47.

20. Kilbridge PM, Welebob EM, Classen DC. Development of the Leapfrog methodology for evaluating hospital implemented inpatient computerized physician order entry systems. Qual Saf Health Care. 2006;15(2):81-4.

21. Simpao AF, Ahumada LM, Desai BR, Bonafide CP, Gálvez JA, Rehman MA, et al. Optimization of drugdrug interaction alert rules in a pediatric hospital's electronic health record system using a visual analytics dashboard. J Am Med Inform Assoc. 2014.

22. Dixon BE, Zafar A. Inpatient Computerized Provider Order Entry (CPOE): Findings from the AHRQ Portfolio (Prepared by the AHRQ National Resource Center for Health IT under Contract No. 290-04-0016). AHRQ Publication No. 09-0031-EF. Rockville, MD: Agency for Healthcare Research and Quality. January 2009. [cited 2014 Oct 11]. Available from: http://healthit.ahrq.gov/ ahrq-funded-projects/emerging-lessons/computerizedprovider-order-entry-inpatient/inpatientcomputerized-provider-order-entry-cpoe. 
23. Maturity Models. Empower your organization with benchmarking. [Internet]. HIMSS Analytics. Health Information Management Systems Society; 2014 [cited 2014 Oct 11]. Available from: http://www. himssanalytics.org/emram/.

24. Kaushal R, Barker KN, Bates DW. How can information technology improve patient safety and reduce medication errors in children's health care? Arch Pediatr Adolesc Med. 2001;155(9):1002-7.

25. Ferranti JM, Horvath MM, Jansen J, Schellenberger P, Brown T, DeRienzo CM, et al. Using a computerized provider order entry system to meet the unique prescribing needs of children: description of an advanced dosing model. BMC Med Inform and Decis Making. 2011;11:14.

26. Kaushal R, Bates DW, Landrigan C, McKenna KJ, Clapp $\mathrm{MD}$, Federico F, et al. Medication errors and adverse drug events in pediatric inpatients. JAMA. 2001;285(16):2114-20.

27. Bates DW, Leape LL, Cullen DJ, Laird N, Petersen LA, Teich JM, et al. Effect of computerized physician order entry and a team intervention on prevention of serious medication errors. JAMA. 1998;280(15):1311-6.

28. Upperman JS, Staley P, Friend K, Neches W, Kazimer D, Benes J, et al. The impact of hospitalwide computerized physician order entry on medical errors in a pediatric hospital. J Pediatr Surg. 2005;40(1):57-9.

29. Kadmon G, Bron-Harlev E, Nahum E, Schiller O, Haski $\mathrm{G}$, Shonfeld T. Computerized order entry with limited decision support to prevent prescription errors in a PICU. Pediatrics. 2009;124(3):935-40.

30. Walsh KE, Landrigan CP, Adams WG, Vinci RJ, Chessare JB, Cooper MR, et al. Effect of computer order entry on prevention of serious medication errors in hospitalized children. Pediatrics. 2008;121(3):e421-7.

31. Potts AL, Barr FE, Gregory DF, Wright L, Patel NR. Computerized physician order entry and medication errors in a pediatric critical care unit. Pediatrics. 2004;113(1 Pt 1):59-63.

32. Teich JM, Merchia PR, Schmiz JL, Kuperman GJ, Spurr CD, Bates DW. Effects of computerized physician order entry on prescribing practices. Arch Intern Med. 2000;160(18):2741-7.

33. Tierney WM, Miller ME, Overhage JM, McDonald CJ. Physician inpatient order writing on microcomputer workstations. Effects on resource utilization. JAMA. 1993;269(3):379-83.

34. Bates DW, Kuperman GJ, Rittenberg E, Teich JM, Fiskio J, Ma'luf N, et al. A randomized trial of a computerbased intervention to reduce utilization of redundant laboratory tests. Am J Med. 1999;106(2):144-50.

35. Hatfield MD, Cox R, Mhatre SK, Flowers WP, Sansgiry SS. Impact of computerized provider order entry on pharmacist productivity. Hosp Pharm. 2014;49(5):458-65.

36. Shamliyan TA, Duval S, Du J, Kane RL. Just what the doctor ordered. Review of the evidence of the impact of computerized physician order entry system on medication errors. Health Serv Res. 2008;43(1 Pt 1):32-53.
37. Ash JS, Sittig DF, Dykstra R, Campbell E, Guappone K. Exploring the unintended consequences of computerized physician order entry. Stud Health Technol Inform. 2007;129(Pt 1):198-202.

38. Ash JS, Sittig DF, Poon EG, Guappone K, Campbell E, Dykstra RH. The extent and importance of unintended consequences related to computerized provider order entry. J Am Med Inform Assoc. 2007;14(4):415-23.

39. Ash JS, Sittig DF, Dykstra R, Campbell E, Guappone K. The unintended consequences of computerized provider order entry: findings from a mixed methods exploration. Int J Med Inform. 2009;78 Suppl 1:S69-76.

40. Campbell EM, Sittig DF, Guappone KP, Dykstra RH, Ash JS. Overdependence on technology: an unintended adverse consequence of computerized provider order entry. AMIA Annu Symp Proc. 2007;94-8.

41. Zhang Y, Padman R, Levin JE. Paving the COWpath: data-driven design of pediatric order sets. J Am Med Inform Assoc. 2014;21(e2):e304-11.

42. Leu MG, Morelli SA, Chung OY, Radford S. Systematic update of computerized physician order entry order sets to improve quality of care: a case study. Pediatrics. 2013;131 Suppl 1:S60-7.

43. Ash JS, Stavri PZ, Dykstra R, Fournier L. Implementing computerized physician order entry: the importance of special people. Int J Med Inform. 2003;69(2-3):23550.

44. Brady PW, Brinkman WB, Simmons JM, Yau C, White $\mathrm{CM}$, Kirkendall ES, et al. Oral antibiotics at discharge for children with acute osteomyelitis: a rapid cycle improvement project. BMJ Qual Saf. 2014;23(6):499507.

45. Parker MW, Schaffzin JK, Vecchio Lo A, Yau C, Vonderhaar K, Guiot A, et al. Rapid adoption of Lactobacillus rhamnosus GG for acute gastroenteritis. Pediatrics. 2013;131 Suppl 1:S96-102.

46. Schaffzin JK, Prichard H, Bisig J, Gainor P, Wolfe K, Solan LG, et al. A collaborative system to improve compartment syndrome recognition. Pediatrics. 2013;132(6):e1672-9.

47. Bekmezian A, Chung PJ, Yazdani S. Standardized admission order set improves perceived quality of pediatric inpatient care. J Hosp Med. 2009;4(2):90-6.

48. Walsh KE, Adams WG, Bauchner H, Vinci RJ, Chessare JB, Cooper MR, et al. Medication errors related to computerized order entry for children. Pediatrics. 2006;118(5):1872-9.

49. Institute of Medicine. Guidelines for clinical practice: from development to use. Field MJ, Lohr KN, editors. Washington, DC: National Academies Press; 1992.

50. Cabana MD, Rand CS, Powe NR, Wu AW, Wilson MH, Abboud P-AC, et al. Why don't physicians follow clinical practice guidelines? JAMA. 1999;282(15):145865.

51. Shiffman RN, Liaw Y, Brandt CA, Corb GJ. Computerbased guideline implementation systems a systematic review of functionality and effectiveness. J Am Med Inform Assoc. 1999;6(2):104-14. 
52. Damiani G, Pinnarelli L, Colosimo SC, Almiento $\mathrm{R}$, Sicuro L, Galasso R, et al. The effectiveness of computerized clinical guidelines in the process of care: a systematic review. BMC Health Serv Res. 2010;10(1):2.

53. Bell LM, Grundmeier R, Localio R, Zorc J, Fiks AG, Zhang $\mathrm{X}$, et al. Electronic health record-based decision support to improve asthma care: a cluster-randomized trial. Pediatrics. 2010;125(4):e770-7.
54. Forrest CB, Fiks AG, Bailey LC, Localio R, Grundmeier $\mathrm{RW}$, Richards T, et al. Improving adherence to otitis media guidelines with clinical decision support and physician feedback. Pediatrics. 2013;131(4):e107181.

55. Szajewska H, Skorka A, Ruszczynski M, GieruszczakBialek D. Meta-analysis: Lactobacillus GG for treating acute diarrhoea in children. Aliment Pharmacol Ther. 2007;25(8):871-81. 